\title{
EL MODELO TOD (TRANSIT-ORIENTED DEVELOPMENT): ESTUDIO DE CASOS INTERNACIONALES Y PROCESO DE IMPLEMENTACIÓN
}

\author{
Armando Ortuño Padilla \\ Departamento de Edificación y Urbanismo. Universidad de Alicante, arorpa@ua.es \\ Graciela Fernández Morote \\ Planificación del transporte.WSP/Parsons Brinckerhoff, gracielamorote@gmail.com \\ Patricia Fernández Aracil \\ Instituto del Agua y de las Ciencias Ambientales. Universidad de Alicante, patricia@ua.es
}

\section{RESUMEN}

En este artículo se presenta un repaso a escala internacional de la aplicación del modelo de desarrollo urbanístico conocido como Transit-Oriented Development (TOD) en diversas partes del mundo, derivado del trabajo de campo de los autores: sus características, condicionantes y resultados. Así, el estudio de los casos expuestos en Estados Unidos, Holanda o Alemania, puede servir como base para una futura implementación en España considerando sus factores de éxito: el compromiso del sector público, de las empresas explotadoras del transporte público y la participación del sector inmobiliario.

Palabras clave: Desarrollo Orientado al Transporte; comparación internacional; planificación urbana y territorial.

\section{ABSTRACT}

This article synthesizes the results of a field work carried out in USA, The Netherlands and Germany related to the Transit-Oriented Development (TOD) model concerning procedures, determinants, and results. Thus, the study of the international cases can serve as a

Fecha de recepción: enero 2015.

Fecha de aceptación: octubre 2015. 
basis for future implementation in Spain, considering success factors such as: public sector commitment, transport operator companies and development agencies.

Keywords: Transit-Oriented Development; international comparison; city and regional planning.

\section{INTRODUCCIÓN}

Escribiendo en términos de planificación urbana, es posible citar dos patrones urbanísticos principales cuyas características conforman la definición de un modelo de urbano u otro: ciudad compacta o ciudad dispersa. Una parte mayoritaria de los autores relacionados con esta temática considera el modelo de ciudad dispersa menos sostenible que el compacto (Moliní y Salgado, 2010), debido sobre todo a las consecuencias negativas que genera, entre ellas: contaminación ambiental, congestión del tráfico, mayor consumo de recursos naturales o mayor coste de prestación de servicios públicos (Henry, 2007).

Con el objetivo de combatir los efectos negativos de los desarrollos urbanos dispersos y en baja densidad, así como la dependencia del vehículo privado motorizado, nace el modelo denominado Transit-Oriented Development (Desarrollo Orientado al Transporte), más conocido por sus siglas en inglés: TOD -como será citado en adelante-. Este modelo consiste en fomentar el desarrollo urbanístico en torno a las estaciones de transporte público, en un área de influencia máxima de $800 \mathrm{~m}$, de tal forma que las densidades en ese entorno puedan ser medias-altas y la distribución del espacio urbano permita la mezcla de usos (Curtis, 2012; Renne, 2009). Se trata de un modelo alineado con el urbanismo sostenible (Calthorpe, 1993), pues mediante la integración de urbanismo y transporte, se pretende cumplir con tres de sus objetivos fundamentales (Cervero y Kockelman, 1997):

a) Reducir el número de viajes motorizados.

b) De entre los viajes generados, incrementar la cuota de aquellos no motorizados en el reparto modal (caminar o bicicleta).

c) De entre los viajes motorizados generados, reducir las distancias de viaje e incrementar los niveles de ocupación de los vehículos.

En el caso de España, una de las definiciones más exhaustivas de urbanismo identificado como sostenible procede de la mano de los indicadores de sostenibilidad de Rueda (2007), cuyo paradigma de desarrollo sostenible en las ciudades se basa en cuatro pilares que dan cuenta de cuatro características esenciales: compacidad, complejidad, eficiencia y estabilidad.

La definición del modelo TOD según City and County of Denver (2006) es la siguiente: «TOD es más que un simple desarrollo urbano cercano al transporte público. Un TOD de éxito es capaz de crear barrios agradables, llenos de actividad y adaptados a las necesidades de los peatones; con una mezcla viviendas, comercio y la posibilidad de elegir entre diversos modos de transporte; una simbiosis de largo plazo entre los agentes públicos, privados y los propios residentes; además, facilita el acceso a los lugares de trabajo en la región, los centros administrativos o gubernamentales, los equipamientos sanitarios y los destinos culturales o de ocio». 
Con todo, y en esta introducción teórica, merece la pena resaltar que el precursor del trasfondo conceptual del TOD fue Arturo Soria y Mata, con su propuesta de «Ciudad-Lineal» como patrón urbanístico aplicable en Madrid (Soria, 1882 y 2004).

Partiendo de los conceptos referidos, el objetivo del trabajo que nos ocupa es presentar la aplicación del modelo TOD, por medio de sus características, condicionantes y resultados obtenidos a escala internacional, -información que ha sido extraída a partir de diversas estancias y trabajos de campo de los autores-. Así, en los siguientes apartados, se describen casos de estudio particulares en Estados Unidos, Holanda y Alemania. No obstante, es preciso tener presente a lo largo del texto que, a pesar de encontrar aspectos comunes entre los diferentes casos estudiados de TOD, no se trata de un modelo unívocamente definido ni cuya aplicación resulte sistemática, sino que, para ponerlo en práctica, se hace imprescindible su contextualización previa en un área determinada del territorio.

\section{EL CASO DE OTHELLO STATION, SEATTLE (EE.UU.)}

La estación de tranvía de Othello se encuentra en el barrio Martin Luther King/New Holly, a unos $10 \mathrm{~km}$ al sur de la ciudad de Seattle (EE.UU.), cuya población asciende a unos seiscientos mil habitantes, resultando más de tres millones en su área metropolitana.

La construcción del barrio finalizó en el año 2005, mientras que su estación de tranvía se inauguró en 2009. Pero, ahondando en sus orígenes, la idea de extender la línea de tranvía hacia el sur de Seattle se gestó a finales de la década de los noventa, proyecto en el cual participaron:

a) El Ayuntamiento de Seattle,

b) Sound Transit, compañía de transporte público, que opera el autobús, el tranvía y los servicios de cercanías en el área metropolitana de Seattle, y

c) La autoridad de mercado inmobiliario de Seattle: Seattle Housing Authority (SHA, en adelante).

En los albores de esa idea también se contemplaba el hecho de ligar la planificación del transporte -fundamentada básicamente en la localización de estaciones- con el desarrollo inmobiliario (Department of Transportation Seattle Government, 2014).

Antes de la intervención, en el área de la estación vivían unos 4.000 residentes, ocupando el uso residencial aproximadamente el $60 \%$ del suelo, con una mayoría de viviendas en baja densidad, un $13 \%$ de uso comercial y un $17 \%$ de uso del suelo vacante. Las rentas familiares eran del $62 \%$ de la mediana de la región con una media de 3,1 personas por vivienda, muy superior al 2,0 del conjunto del Área Metropolitana de Seattle. En 1999 se proyectaba un número de viajeros de 1.200 diarios (BAE, Pittman \& Hames, 1999).

El Plan se aprobó finalmente en 1999, basándose en la mezcla de usos urbanos del suelo, cuyas necesidades de movilidad serían servidas sobre todo por el tranvía a través de la estación de Othello -cuya frecuencia oscila entre los siete y los quince minutos durante todo el día-, aunque también por medio del transporte en autobús. Se propuso una reordenación de los usos del suelo en el entorno de la estación, incluyendo comercio de barrio, restaurantes y locales de ocio, así como equipamientos educativos y sociales dirigidos al peatón (Fig. 1). 
Figura 1

CONCEPTO DE DISEÑO URBANO PARA LA ESTACIÓN DE OTHELLO

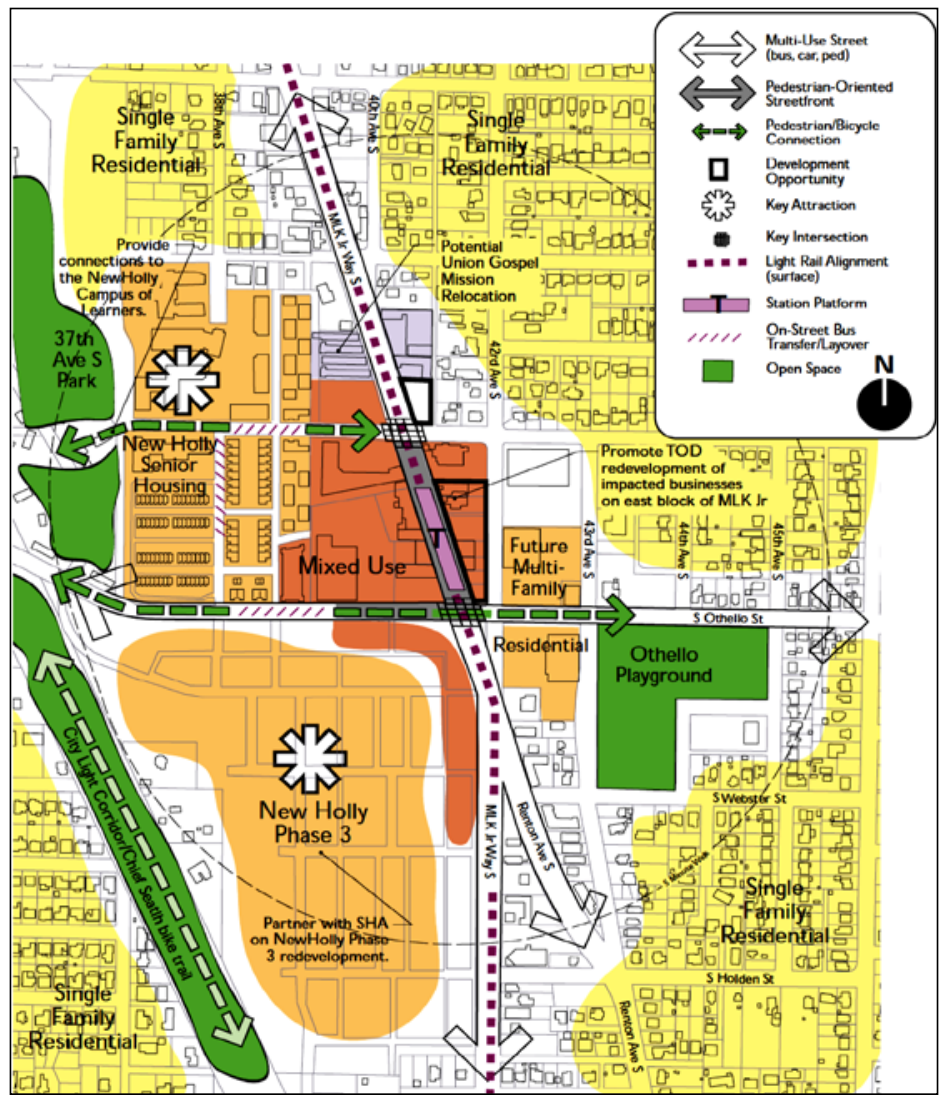

Fuente: City of Seattle (2014).

Desde entonces, SHA ha construido aproximadamente 1.400 viviendas, tanto en régimen de alquiler, como en propiedad para diversos niveles de renta, considerando aproximadamente un tercio de las viviendas para alquiler de rentas bajas, otro tercio para alquiler en el mercado libre y el resto en propiedad. La inversión total ascendió a 340 millones de dólares, la cual se materializó merced a inversión privada, préstamos blandos y subvenciones estatales o procedentes de otras administraciones.

Gran parte del estacionamiento gratuito en los alrededores de la estación se sustituyó por otro más pequeño y de pago, con el objetivo de eliminar la demanda del estacionamiento de larga duración que no utilizaba el transporte público. El diseño y explotación de ese nuevo estacionamiento se consensuó con los comerciantes del entorno de la estación para favorecer su actividad económica. Así, existe un pago cada dos años de $65 \$$ por vehículo para residentes y de 30 \$ para visitantes en un radio de $400 \mathrm{~m}$ alrededor de la estación, que cubre días laborables desde las 7:00 hasta las 18:00 h (Department of Transportation Seattle Government, 2014). 
Más recientemente, en abril de 2014, fue adjudicado un nuevo lote de 108 viviendas para rentas bajas (hasta el $60 \%$ de la mediana de ingresos de la región) con $720 \mathrm{~m}^{2}$ de bajos comerciales y cincuenta plazas de estacionamiento -menos de media plaza de estacionamiento por vivienda, para reducir los costes de ejecución y dado que es posible alquilar plazas próximas a la estación, como se ha comentado- a unos metros de la estación de Othello. Como la propia compañía de transporte público reconoce: «TOD materializado en forma de bloques de apartamentos cercanos a las estaciones tranviarias es una de las prioridades de SHA» (Sound Transit, 2014).

A la vista de lo señalado, los resultados de la intervención fueron satisfactorios, como indica la citada reciente adjudicación para desarrollar las 108 viviendas o los más de 2.000 viajeros diarios que utilizaron el tranvía en 2010, casi el doble de lo proyectado en 1999.

Con respecto a la situación en la actualidad, el trabajo de campo ha permitido dilucidar el avance en alguna ejecución de bloques de viviendas con bajos comerciales (Fig. 2), íntegramente alquilados, cuyas particularidades físicas y sociológicas ponen de manifiesto, respectivamente, la calidad arquitectónica del edificio y las buenas perspectivas de desarrollo inmobiliario para los próximos años, según manifestaban muchos de sus residentes o propietarios de suelo vacante, quienes albergan expectativas de revalorización del mismo.

Figura 2

NUEVO EDIFICIO RESIDENCIAL DE ALQUILER CON BAJOS COMERCIALES EN EL ENTORNO DE LAESTACIÓN TRANVIARIA DE OTHELLO

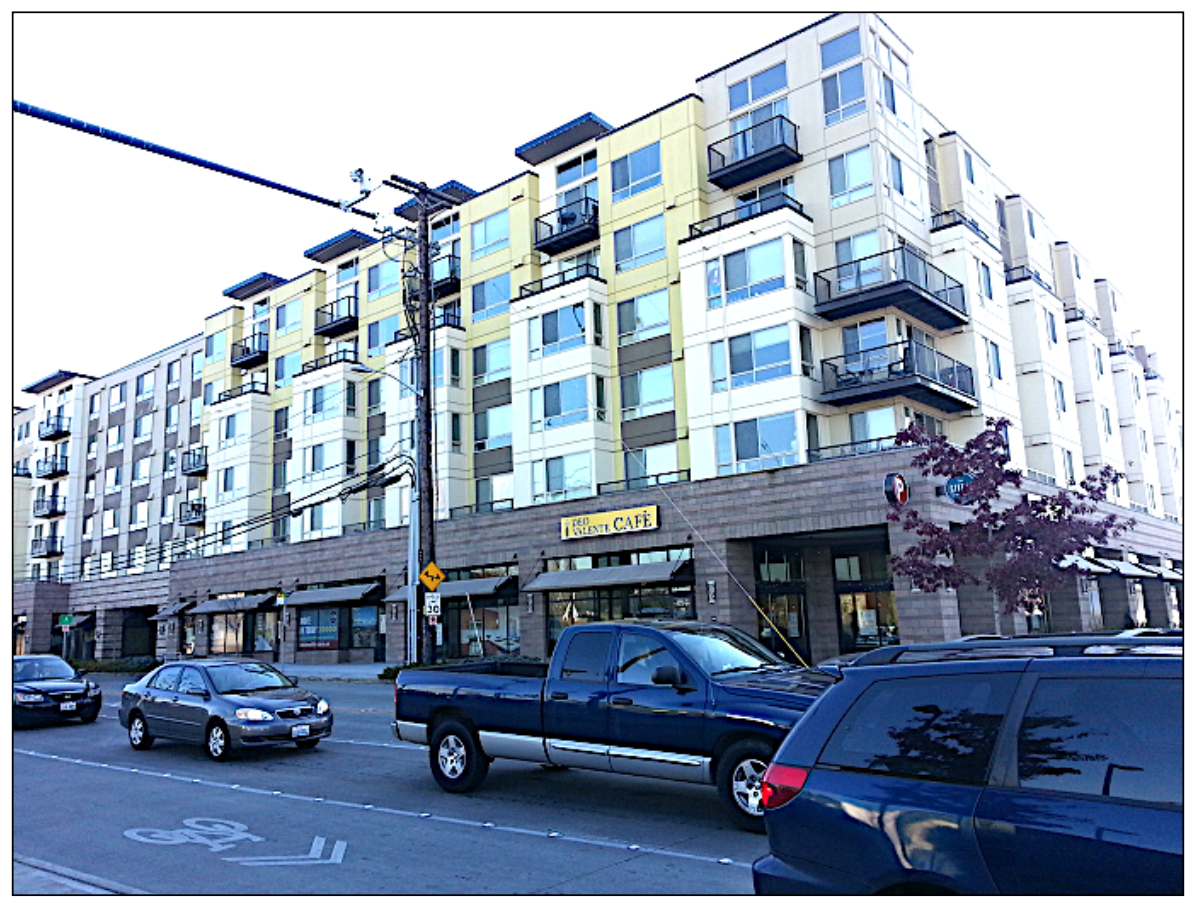

Foto de los autores. 


\section{EL CASO DE OHLONE-CHYNOWETH COMMONS, SAN JOSÉ (EE.UU.)}

La estación de Ohlone-Chynoweth fue inaugurada en 1991 y se encuentra a unos 10 $\mathrm{km}$ al sur de la ciudad de San José (Condado de Santa Clara), junto a la intersección de dos importantes autovías del área metropolitana. En los años noventa, cuando el proyecto de TOD inició su andadura, estaba dotada de un park\&ride de más de 1.100 plazas cuya una ocupación en días laborables no superaba el $25 \%$ de su oferta de estacionamiento (Fig. 3). Fue esta circunstancia la que propició que la Autoridad de Transporte del Valle de Santa Clara (VTA) plantease la propuesta de TOD, apoyada seguidamente por el municipio de San José (National Research Council, 2002 y 2004).

Figura 3

ESTACIÓN DE OHLONE-CHYNOWETH ANTES DEL PROYECTO DE TOD EN LOS AÑOS NOVENTA. EN EL CENTRO DE LA IMAGEN SE PUEDE VER LA PARADA DEL TRANVÍA Y EL ESTACIONAMIENTO DE MÁS MIL PLAZAS

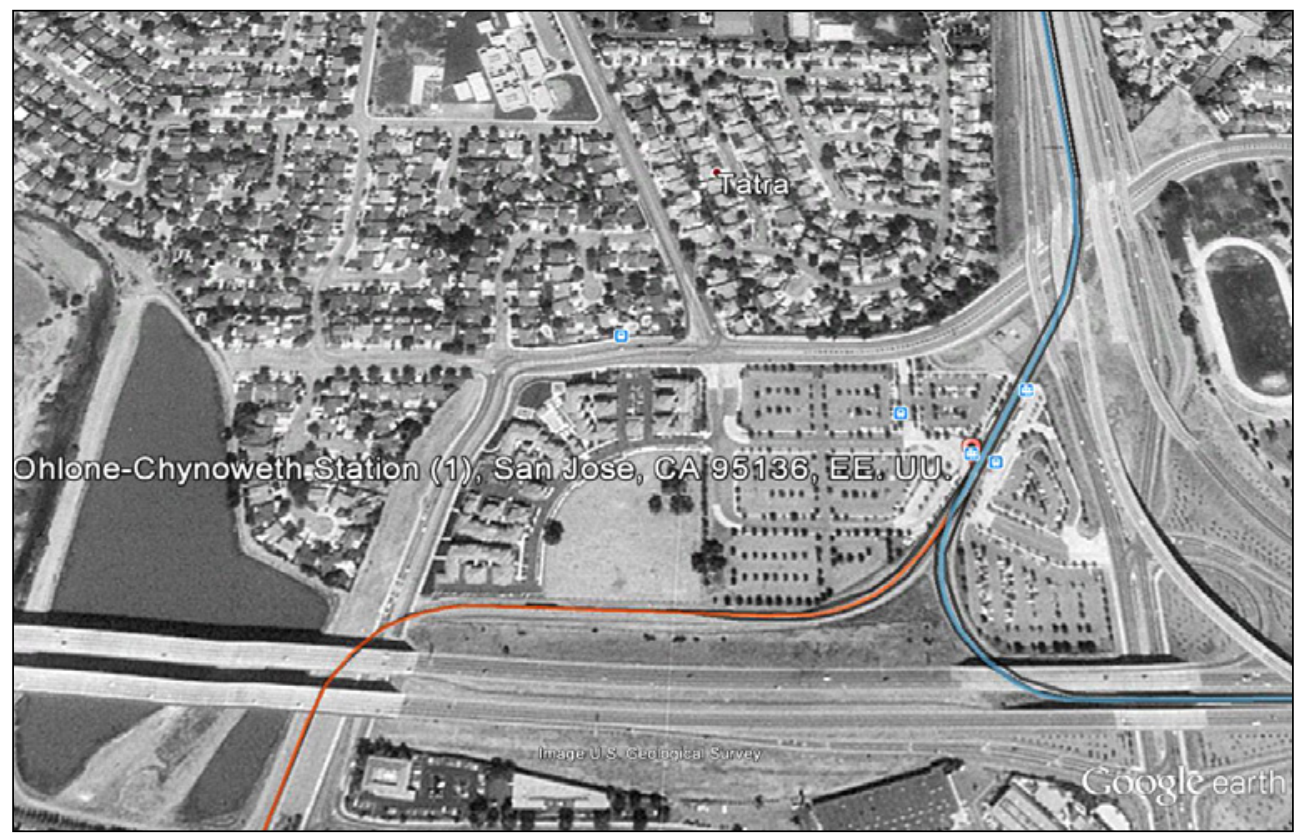

Fuente: Google Earth.

De este modo, la operación de implantación del modelo TOD (Fig. 4) consistió en sustituir el $75 \%$ del espacio dedicado a estacionamiento por 195 viviendas sociales en régimen de alquiler -con el objetivo dar alojamiento a personas que se encontraran entre el 30 y el 60 $\%$ de la mediana de los ingresos del Condado de Santa Clara-, ubicadas en edificios de tres plantas y permaneciendo únicamente 240 plazas de estacionamiento park\&ride gratuito. Este incremento en la densidad residencial se acompañó de $400 \mathrm{~m}^{2}$ de superficie comercial, una guardería con capacidad para 40 niños y un parque común interior a las viviendas de $370 \mathrm{~m}^{2}$ (Breznau, 2004). 
Figura 4

ESTACIÓN DE OHLONE-CHYNOWETH EN LAACTUALIDAD. EN EL CENTRO DE LA IMAGEN SE PUEDE COMPROBAR CÓMO HA SIDO OCUPADO POR VIVIENDAS GRAN PARTE DEL ESTACIONAMIENTO

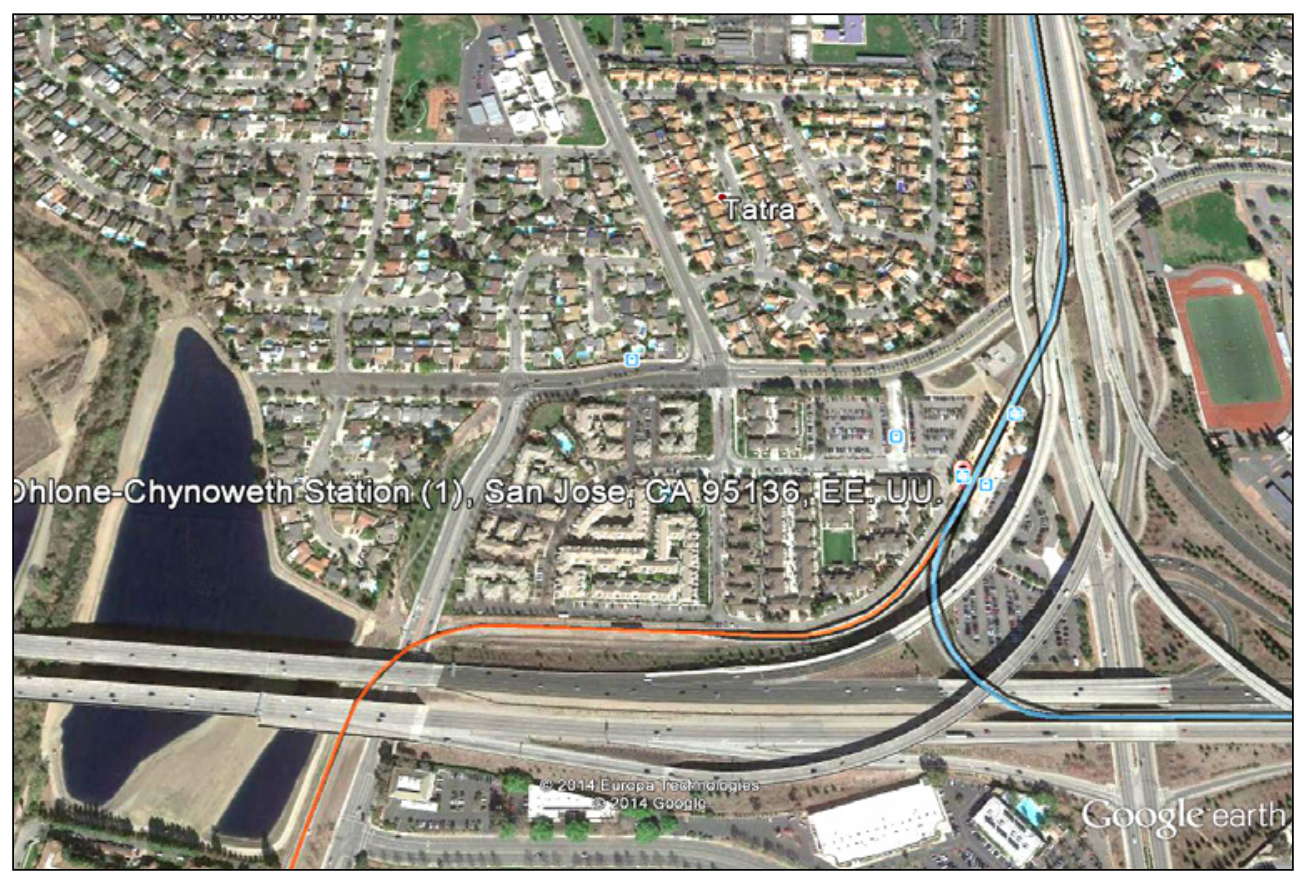

Fuente: Google Earth.

La aprobación del proyecto no estuvo exenta de dificultades ya que inicialmente se plantearon las viviendas en el mercado libre sin apenas respuesta de los promotores. Ante esta eventualidad, las viviendas pasaron a calificarse como sociales y se le adjudicó la ejecución del proyecto a una empresa sin ánimo de lucro: Eden Housing. En ese momento, fueron los vecinos del entorno quienes se opusieron al proyecto, puesto que previamente ya habían sido ejecutadas otras 135 viviendas sociales en el barrio. De esta forma, el proyecto de TOD sólo pudo salir adelante cuando recibió el apoyo de diversos colectivos como Sierra Club, Silicon Valley Manufacturers Association y Greenbelt Alliance, que representaban desde asociaciones ecologistas, hasta entidades ligadas a la alta tecnología industrial (National Research Council, 2004).

El proyecto fue finalizado en 2001, con un importe total de 31 millones de dólares, cubierto con fondos locales, regionales y con subsidios para la empresa promotora. De esta forma, en el año 2002 y a modo de resultados preliminares, las viviendas estaban ocupadas íntegramente, si bien el comercio se resistió algunos años encontrándose en la actualidad completo con una cafetería, una tienda de ultramarinos y una farmacia (Fig. 5). Así mismo, respecto de las cuestiones relacionadas con la movilidad, la media de vehículos por vivienda en la operación era de 2,07 mientras que en el entorno de baja densidad del área metropolitana aumentaba a 2,31. Finalmente, en cuanto al número de millas recorridas por 
familia, era de 21.213 frente a 24.235 en el área metropolitana, con lo que sí se aprecia la diferencia en términos de menor dependencia del vehículo privado (Department of Transportation California Government, 2014).

Figura 5

ESTACIÓN DE OHLONE-CHYNOWETH EN LAACTUALIDAD. EN EL CENTRO DE LA IMAGEN SE PUEDEN OBSERVAR DIVERSOS ESTABLECIMIENTOS COMERCIALES ASI COMO LA TIPOLOGÍA DE VIVIENDAS QUE COMPONEN LA INTERVENCIÓN Y LA CALIDAD DEL ESPACIO PÚBLICO

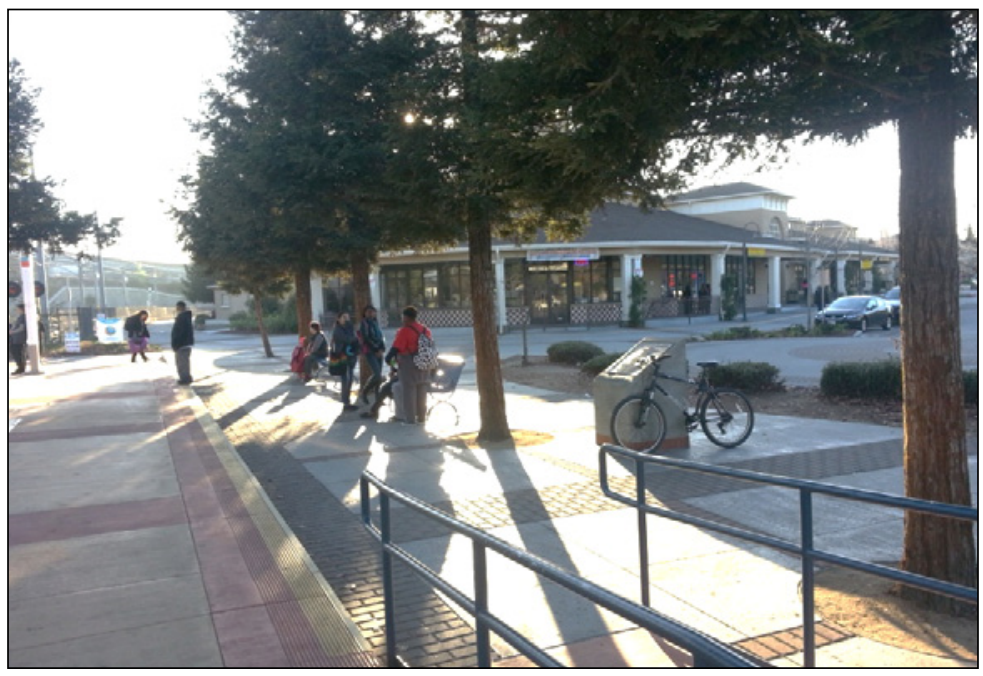

Foto de los autores.

\section{EL CASO DE PORTLAND (EE.UU.)}

Portland es un ejemplo paradigmático en Estados Unidos -casi 600.000 habitantes en la ciudad y más de 2 millones en el área metropolitana- pues, a diferencia de otras ciudades estadounidenses caracterizadas por su baja densidad predominante, sus calles gozan de gran actividad urbana y en ellas conviven peatones, ciclistas, vehículos privados, autobuses y otros sistemas de transporte público.

Esto es debido a que la ciudad posee un claro y definido límite al crecimiento urbano, que ha permitido contener el desarrollo de la baja densidad, favoreciendo la compacidad de la ciudad y prestando atención a las necesidades de un ambiente urbano de calidad. Fue en el año 1973 cuando en el Estado de Oregón se iniciaron los primeros pasos para llevar a cabo un plan integral de preservación de espacios naturales y así limitar el crecimiento disperso, convirtiéndose Portland en su máximo exponente y lugar de referencia para el conjunto del país (Gibson y Abbott, 2002; Putters, 2008).

Fue en los noventa cuando se intensificó la idea de invertir en proyectos de ciudad compacta con mezcla de usos cerca de las estaciones de ferrocarril y corredores servidos por líneas de autobuses de alta frecuencia (TOD, por definición). Esta concepción, diseñada por Metro (Agencia Regional de Portland y su Área Metropolitana, que coordina el desarrollo 
urbanístico y del transporte público), quedó reflejada en la estrategia de crecimiento urbano a cincuenta años vista: «2040 Growth Concept» (Oregon Metro, 2011). Específicamente, la estrategia cristaliza a través del «Metro TOD Program» (Metro, 2014), que está diseñado para proporcionar incentivos -fundamentalmente en forma de modestas subvenciones-, a los promotores privados, para que construyan barrios de alta densidad urbana con mezcla de usos cerca de las estaciones de transporte público, bajo la premisa de que estos proyectos pueden ser más caros o soportar riesgos financieros superiores frente a otros más convencionales.

Los promotores, públicos o privados, son elegidos en procesos de concurrencia competitiva bajo determinados requerimientos (Oregon Metro, 2012a), entre los que destacan los relacionados con:

- La conexión con el transporte público: la distancia a pie hasta la estación existente o prevista de ferrocarril será como máximo de $800 \mathrm{~m}$, mientras que respecto de las paradas de autobús y tranvía, la distancia será inferior a $400 \mathrm{~m}$.

- La máxima densidad razonable compatible con el entorno.

- El coste por cada viajero inducido por el transporte público es relativamente similar al de otros proyectos.

- La operación tiene el mínimo número de razonable de plazas de estacionamiento.

- La operación reducirá el número de kilómetros recorridos en vehículo privado con respecto a lo que ocurriría de no incluirse el transporte público.

- El proyecto aumentará los espacios y rutas peatonales y ciclistas, siendo éstos visualmente más atractivos y seguros.

Diez años después del arranque del «Metro TOD Program», TriMet (Agencia de transporte público que opera en el ámbito espacial de Metro) ya había ejecutado 85 estaciones de tranvía -conocido como $M A X$ - sobre 30 existentes, y el número de corredores de alta frecuencia para autobuses había pasado de 4 a 12. Simultáneamente, más de la mitad de los pasajeros entre los nuevos barrios construidos se desplazan en transporte público, superando, por tanto, los viajes en vehículo privado. Hasta esa fecha, se habían ejecutado casi 3.000 viviendas para todo tipo de perfiles socioeconómicos, con más de $12.000 \mathrm{~m}^{2}$ de superficie comercial y casi $20.000 \mathrm{~m}^{2}$ de oficinas. Así mismo, estos proyectos ocuparon solamente 19 hectáreas, frente a las 196 hectáreas que habría ocupado un desarrollo convencional en baja densidad, pudiendo de esta forma conservar espacio agrícola y ambiental de interés (Oregon Metro, 2014).

Bajo este paraguas de la planificación regional en Portland, seguidamente se explicarán con mayor grado de detalle dos intervenciones de TOD en su área metropolitana, una de las cuales, Centre Commons, ha resultado muy positiva; mientras que la otra, la estación de Beaverton Central (The Round), no lo ha sido tanto hasta la fecha.

\section{EL CASO DE CENTRE COMMONS, PORTLAND (EE.UU.)}

Los albores del TOD en este entorno se remontan a 1994, cuando el Ayuntamiento de Portland y residentes del barrio de Centre Commons comenzaron a negociar sobre el suelo propiedad del Departamento de Transporte de Oregon (ODOT, en adelante), que había cesado sus operaciones de estacionamiento de vehículos en 1990. Finalmente, los vecinos 
del entorno vieron con buenos ojos la idea del TOD en el barrio, siempre y cuando se garantizaran los siguientes aspectos: un acceso peatonal, seguro y mejorado al tranvía $(M A X)$; espacios abiertos y de ocio; altura de las viviendas compatible con las del entorno y la conservación de determinadas especies arbóreas.

En el año 1995, la Portland Development Commission (PDC, en adelante), es decir, la agencia de desarrollo local, elaboró un estudio en el cual se concluía que este espacio reunía las condiciones para favorecer el tipo de crecimiento urbanístico deseado en la región: densidad media-alta próxima a las estaciones tranviarias, una mezcla de distintos tipos de viviendas y revitalización del entorno. En ese momento, el espacio abandonado estaba siendo utilizado de manera informal por usuarios del MAX como park\&ride y como estacionamiento para excursionistas durante los fines de semana.

La PDC compró los suelos a la ODOT en 1996, pero el aumento de los costes de la obra inicialmente previstos y los cambios de las condiciones del mercado amenazaron las calidades del proyecto de forma que, Metro, el Gobierno Regional de Portland, adquirió finalmente los terrenos (National Research Council, 2004).

Se trata de una actuación urbanística finalizada en el año 2000 cuyo importe total ascendió a 33 millones de dólares, con ventajas fiscales tanto para la empresa concesionaria de la obra como para los residentes, con objeto de favorecer el atractivo de la operación. Entre las citadas ventajas fiscales destaca la exención de impuestos sobre la propiedad a los residentes durante un periodo de diez años. El nuevo entorno residencial se sitúa a $8 \mathrm{~km}$ al este del centro de Portland y a cinco minutos a pie de la estación más cercana de tranvía, si bien para llegar a la parada de tranvía hay que acceder a través de una pasarela sobre una autopista que se sitúa justo al borde del sector. También existen en el sector tres líneas de autobús que conectan con otras zonas del área metropolitana. La operación consta de un total de 288 viviendas con una dotación de 0,61 plazas de estacionamiento por vivienda, de las cuales 172 son viviendas sociales para jubilados, 60 viviendas sociales para familias y 56 de libre mercado. Estas viviendas se componen de cuatro bloques de cinco alturas que abrazan un espacio público interior. La operación se completa con una residencia para la tercera edad en la planta baja y una guardería (Fig. 7).

Los resultados en 2002, dos años después de su inauguración, mostraron que el porcentaje de reparto modal en transporte público por motivo trabajo aumentó hasta el $46 \%$ aproximadamente, frente al $31 \%$ preexistente; mientras que para el resto de motivos pasó del 20 al $32 \%$. Para poder valorar estos resultados, sirva que en el año 2000, en el conjunto de la ciudad de Portland, el motivo trabajo alcanzó el 12,3\%. Así mismo, el $30 \%$ de los residentes dispone de menos vehículos de los que disponía antes de variar su residencia a Centre Commons. También cabe destacar que, para aquellos nuevos residentes, los factores decisivos a la hora de decantarse por este entorno fueron: que fuesen viviendas nuevas, su diseño, la calidad del entorno y la proximidad al transporte público.

Sin embargo, aparecen otros factores no tan positivos (National Research Council, 2004; Grady y LeRoy, 2006)

- A pesar del alto porcentaje de jubilados residentes que, junto al tranvía, justificaría la menor necesidad de estacionamientos, existe un déficit para visitantes y a veces para los propios residentes, debiendo desplazarse al barrio vecino para estacionar sus vehículos. 
- Financieramente, las empresas promotoras han tenido problemas dado que las ventas tardaron en fraguarse. Esto pudo ser debido a diversos motivos de índole sociológico, por ejemplo, el hecho de que existieran viviendas sociales pudo desincentivar a potenciales compradores de viviendas adyacentes de libre mercado.

- A pesar de que el proyecto buscaba facilitar la cohesión social mediante la convivencia de residentes de distintas edades en el complejo, esto no ha sucedido así, pues cada edificio ha estado destinado a un perfil diferente de comprador.

En el trabajo de campo realizado, se apreció tanto la calidad del diseño arquitectónico como la del espacio público interior, en el que el peatón es el protagonista, incluyendo juegos para niños, pero también, estacionamiento para vehículos. Este patrón recuerda al modelo holandés de patio o calle compartida: woonerf. Sin embargo, se echó en falta actividad comercial, inexistente; de manera que los residentes tienen que desplazarse al barrio más próximo que, aun quedando relativamente cercano para el desplazamiento a pie, no resulta cómodo para el tránsito; es decir, el proyecto adolece de una cierta autonomía. Además, teniendo presente que Centre Commons está de paso para tomar el MAX, la fachada que mira a la calle principal de acceso a otros barrios sí podría estar dotada de algún comercio cuyas ventas excediesen la demanda propia de Centre Commons al tiempo que contribuirían a esa autonomía.

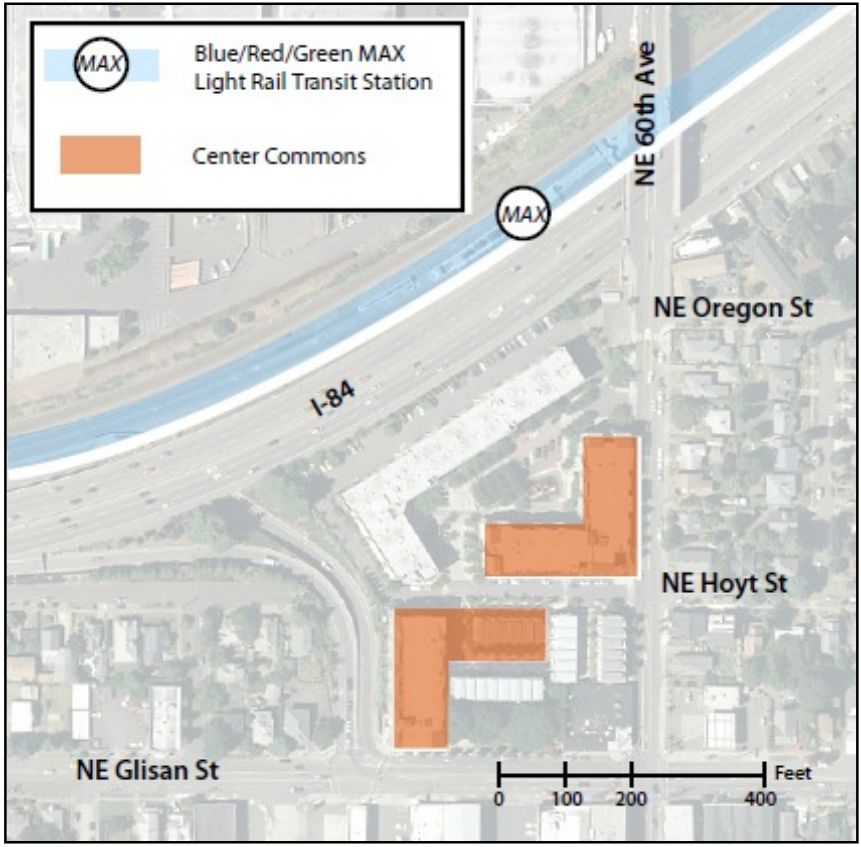

Fuente: Oregon Metro (2012b). 


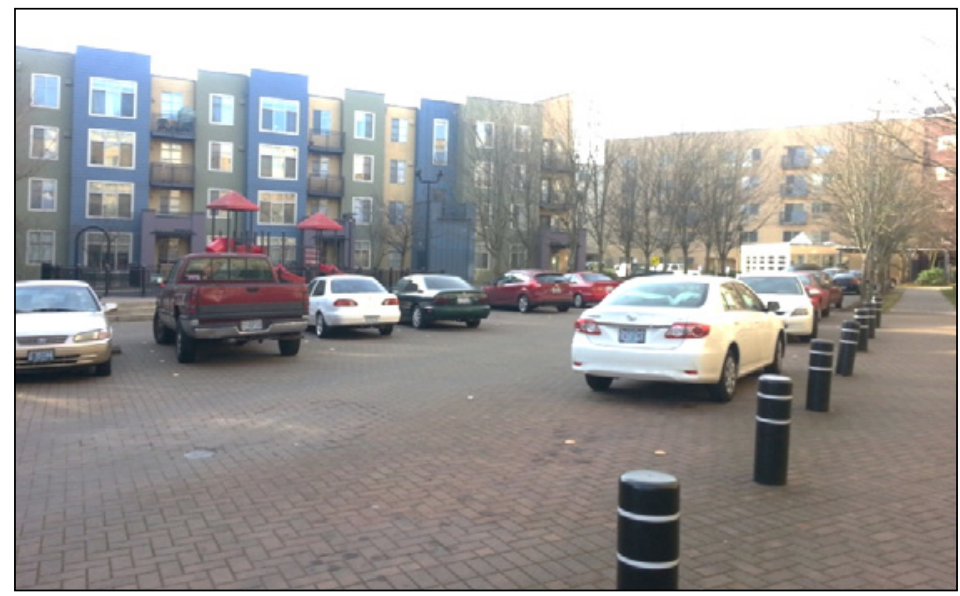

Foto de los autores.

\section{EL CASO DE BEAVERTON CENTRAL, PORTLAND (EE.UU.)}

Situado a $8 \mathrm{~km}$ del centro de Portland, en el municipio de Beaverton, la operación conocida por la plaza circular que rodea a la estación como The Round, fue propuesta en este municipio en 1997 por la empresa privada ganadora del concurso. El proyecto trataba de favorecer la mezcla de usos a través de $21.000 \mathrm{~m}^{2}$ de oficinas y comercios, entre 100 y 150 adosados, 800 plazas de estacionamiento, $4.600 \mathrm{~m}^{2}$ para un centro de interpretación y un hotel de 100 plazas. El presupuesto estimado fue de 50 millones de dólares y desde el principio fue considerado como más costoso que los convencionales debido a su diseño.

De ese modo, TriMet modificó la línea tranviaria para localizar la estación en el punto que estaba llamado a convertirse en el nuevo centro urbano de Beaverton, caracterizado por un desarrollo masivo en baja densidad. Además, se destinaron fondos regionales, se ejecutó un nuevo viario de conexión de The Round con la Autopista más cercana y la localidad de Beaverton eximiría durante 10 años a los residentes del pago de impuestos por su propiedad.

Sin embargo, en ese mismo año de 1998, el promotor entró bancarrota y tuvo que abandonar el proyecto cuando solamente dos edificios estaban construidos parcialmente.

Entre las principales causas atribuibles a este fracaso cabe destacar la inexperiencia del promotor, en tanto en cuanto intentó desarrollar todo el proyecto en lugar de llevarlo a cabo por fases, o el incremento de costes ligados a la cimentación por la existencia de suelos muy orgánicos.

En el año 2001, fue adjudicado el proyecto a otra empresa mucho más experimentada que, sin variar la idea del proyecto, la ajustó más a las demandas del mercado creando una mayor intensidad de usos en torno a la estación y ya sin disponer de subsidios de las administraciones (National Research Council, 2004). 
En la actualidad, existen tres edificios que fueron finalizados en 2003 y un cuarto a punto de inaugurarse. Estos edificios rodean la plaza en cuyo centro se halla la estación del tranvía (MAX) (Fig. 8). La calidad de este espacio público es bastante alta tanto por la amplitud de sus aceras como por los materiales empleados. Entre esos edificios se encuentran: uno de cinco plantas destinado plazas de estacionamiento; otro, también de cinco plantas, para oficinas -íntegramente ocupado y cuya planta baja es un gimnasio- y un tercero, que se compone de 65 unidades en régimen de condominio, de modo que la segunda planta se destina a oficinas mientras que la tercera a viviendas sobre una planta comercial, sobre todo con bares. Por último, el edificio en construcción está destinado a oficinas del ayuntamiento.

Figura 8

ESTACIÓN DE MAX EN THE ROUND. DE FRENTE SE OBSERVA EL EDIFICIO QUE ESTÁ A PUNTO DE INAUGURARSE PARA OFICINAS MUNICIPALES, MIENTRAS QUE A LA IZQUIERDA SE APRECIA EL EDIFICIO DE ESTACIONAMIENTO

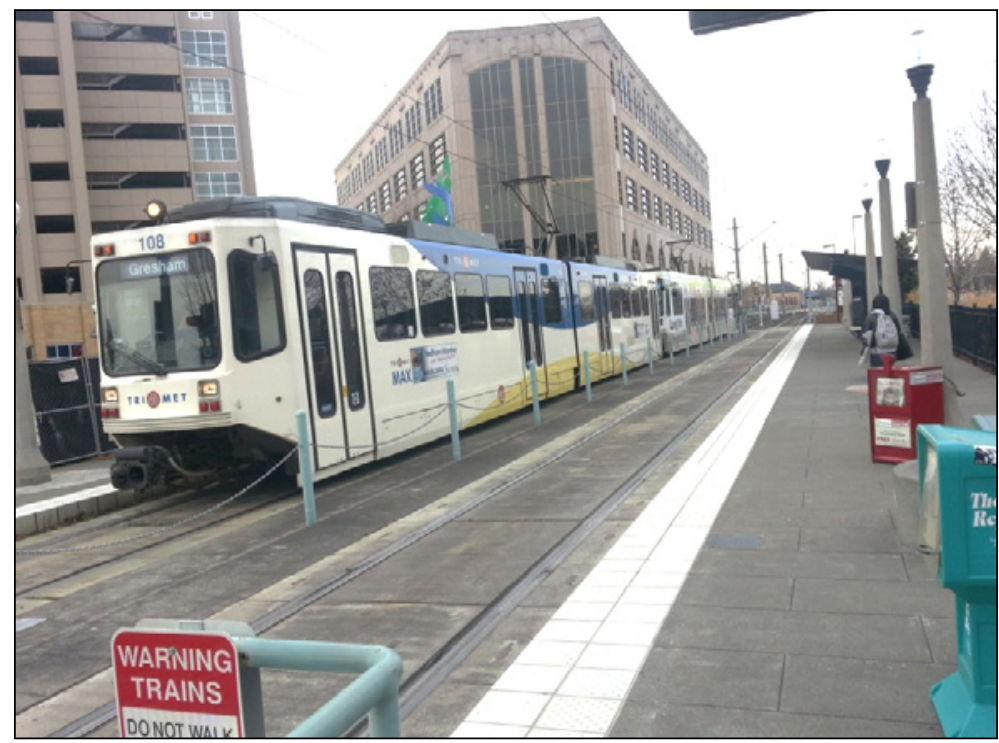

Foto de los autores.

Como resultados de la operación, en términos de movilidad y según una encuesta realizada en 2006 a los residentes, se observó lo siguiente (Dill, 2006):

- Por motivo trabajo, los residentes en The Round utilizaron el transporte público un $41,7 \%$ frente al 7,9\% que lo hacían en el año 2000 el conjunto de los residentes de Beaverton.

- Un 25\% de los residentes pasaron de utilizar el coche al transporte público, mientras que un $8,3 \%$ al revés, lo que arroja un balance claramente positivo.

- Un $77 \%$ de los residentes confesaron utilizar más el transporte público y un $15 \%$ caminar más. 
- Entre los factores más relevantes para la elección de la vivienda, destacaban la accesibilidad al transporte público, el 100\%, las aceras, para un 69\% de los residentes, pero también la proximidad a la autovía, con el $77 \%$.

Sin embargo, a las razones argumentadas sobre el fracaso inicial de The Round, el trabajo de campo permitió advertir que la operación no es más que un grano de arena en el desierto de baja densidad, perfectamente preparado para el coche, dotado de buenos ejes viarios y con una gran oferta comercial (dos grandes superficies a menos de un kilómetro de la estación). Prueba de que el consistorio no acaba de creer en la operación es que, junto al edificio que está ejecutando, también se está finalizando otro estacionamiento en superficie, y ello a pesar de que la demanda de estacionamiento en el edificio destinado a ese uso no supera la mitad de su oferta.

\section{EL CASO DE ZUID-HOLLAND (PAÍSES BAJOS)}

Este caso resulta de especial interés, tanto por la escala del proyecto, que ha precisado de un acuerdo regional, como por la adaptación al periodo de crisis, dado que el proyecto nació con anterioridad a los efectos de la misma. Además, el acuerdo alcanzado con la compañía concesionaria de los ferrocarriles holandeses resulta ejemplar, tal y como se tendrá oportunidad de comprobar.

En el año 2004, la «Bestuurlijk Platform Zuidleugel» (Plataforma del ala sur de Holanda, BPZ en adelante), un ente compuesto por administraciones locales y regionales de la provincia del sur de Holanda, junto con la NS -compañía concesionaria del servicio ferroviario- y prorail -titular de la infraestructura-, decidieron revisar las discordancias entre las dinámicas urbanizadoras y la planificación del transporte. El proyecto llamado Stedenbaan fue así planteado para materializar (Atelier, 2007): la creación de un sistema de transporte público de alta frecuencia, aprovechando la red ferroviaria existente, y un plan de desarrollo urbanístico a escala regional a lo largo de esas estaciones ferroviarias.

El proyecto de TOD en esta zona constituye la columna vertebral del transporte público en una región de casi cuatro millones de habitantes y una densidad de $1.000 \mathrm{hab} / \mathrm{km}^{2}$, de las más altas del planeta, a lo largo de una línea ferroviaria existente de $150 \mathrm{~km}$ entre Leiden y Dordrecht, siguiendo los patrones de un modelo policéntrico de ciudades, con una amplia autonomía en la planificación urbana y donde destacan dos importantes ciudades: Rotterdam y La Haya, con más de medio millón de habitantes en zona urbana en cada una de ellas (Urban Unlimited, 2005; Zonneveld, 2010).

El principal acuerdo, de carácter voluntario, al que se llegó entre los organismos pertenecientes a la plataforma fue el siguiente (Casabella y Frenay, 2009):

- Por un lado, BPZ construiría 40.000 viviendas y 1,2 millones de $\mathrm{m}^{2}$ de oficinas en torno a las estaciones de tren en el periodo 2010-2020, lo que supone, respectivamente, un tercio y dos tercios de las previsiones totales de demanda de la BPZ.

- Por otro lado, la NS, se comprometía a aumentar la frecuencia de los servicios ferroviarios, de $15^{\prime}$ a 10'. Este compromiso es muy relevante en términos de comodidad para el viajero de transporte público, ya que con frecuencias inferiores a los 10' se dirige directamente a la estación, sin necesidad de comprobar el horario. 
Tras estudios previos, tanto a escala territorial, como específicos sobre cada una de las estaciones -relativos a: la accesibilidad en transporte público y en vehículo privado; las densidades residenciales y de empleo; la mezcla de usos; el suelo vacante en un radio de $1.200 \mathrm{~m}$ alrededor de la estaciones, así como los condicionantes paisajísticos y medioambientales- se definieron nueve tipos de estaciones según su potencialidad: áreas rurales, pequeñas villas, afueras de las ciudades, ciudades del futuro, áreas de negocio, Randstad $H u b s$, ciudades creativas, centros de ciudades y nudos suprarregionales. En este sentido, también se llegó a la conclusión de que, siguiendo patrones similares de densidad urbanística a los que se habían dado hasta la fecha en el entorno de las estaciones, existía espacio suficiente para acomodar más de las 40.000 viviendas y 1,2 millones de metros de oficinas que los estudios de demanda habían concluido se precisarían en el horizonte de 2020 (Connected Cities, 2014).

También, merece la pena destacar que la elección de un radio de influencia de $1.200 \mathrm{~m}$ alrededor de las estaciones -superior a los $800 \mathrm{~m}$ que de media se han establecido en otros casos internacionales- se debe a que, en el acceso a las estaciones ferroviarias, la bicicleta alcanza un porcentaje modal muy importante y su radio de influencia es superior (Coster, 2013).

Si en los albores del proyecto eran 11 los municipios que lo componían, en 2011 ya eran 47, de modo que, ese mismo año, el proyecto fue ampliado a otras líneas de transporte público como metro, tranvía o autobús, pasando a llamarse el proyecto StedenbaanPlus (o Stedenbaan+). Esto provocó que para, aproximadamente, el 70\% de las viviendas se adoptase como objetivo que se encontrasen en el área de influencia de las estaciones y paradas de transporte público.

No obstante, la llegada de la crisis económica propició que las expectativas de demanda de vivienda y oficinas quedasen obsoletas. De hecho, en cuanto a las viviendas, para el año 2020 la demanda se estima en unas 27.000 frente a las 40.000 iniciales (Progammabureau Stedenbaan, 2011).

Por lo que respecta a las oficinas, en décadas anteriores se construyeron hasta 13 millones de metros cuadrados de oficinas, de modo que el exceso de oferta y el hecho de que quedasen muchas oficinas con formatos antiguos, originó que aproximadamente el $15 \%$ del espacio para este uso quedara vacante, lo que unido a la crisis económica, nuevos métodos de trabajo que requieren menos espacio por trabajador y la reducción de empleados por las administraciones ha provocado que, en la actualidad, ese porcentaje se eleve hasta un $30 \%$ aproximadamente.

Esto resulta muy importante para llevar a cabo la implantación del modelo TOD, porque el número de pasajeros procedentes de oficinas se considera muy elevado pero, en todo caso, las preferencias del mercado apuntan a una predilección por localizaciones en nodos multimodales en el centro de las ciudades, por lo que Stedenbaan goza de una gran ventaja.

En lo que respecta al papel de los promotores privados - no incluidos formalmente en el proyecto-, se ha demostrado que el aumento de frecuencia de los servicios de transporte público planificado arroja un impacto de entre el 1 y el $2 \%$ de aumento en los precios de las viviendas. La cuestión para los años venideros es si este incremento supone un estímulo suficiente para los promotores de cara a invertir en torno a las estaciones (Geurs et al., 2012).

Además, no hay que olvidar que muchos residentes prefieren vivir en lugares más espaciosos y dependientes del automóvil (Heins et al., 2002; Howley, 2009). 
Otro actor importante es la compañía de ferrocarriles holandeses, NS, quien ha señalado que solamente aumentará la frecuencia si considera que los costes de explotación serán cubiertos, lo que ahora resulta más complicado por las razones expuestas. En todo caso, uno de los frutos del proyecto ha sido la ampliación de la capacidad ferroviaria en Delft (entre Rotterdam y La Haya) de dos a cuatro vías, lo que permitirá aumentar las frecuencias del ferrocarril.

Finalmente, pero no menos importante, el incremento de socios en Stedebaan + también plantea nuevas fórmulas de gobernanza; la administración regional y la NS cooperan estrechamente, pero resulta más difícil en los municipios y para el resto de actores (Geurs et al., 2012). Por ejemplo, de los municipios pequeños se piensa que pueden aportar poco al proyecto porque tienen suelo vacante en nudos de carreteras, con lo que no acaban de observar las ventajas de reconducir su crecimiento hacia las proximidades de las paradas de transporte público. En cuanto a los grandes, como Rotterdam o La Haya, consideran el proyecto de TOD como una cuestión más de las muchísimas que han de gestionar en el día a día.

En 2012, comenzó una nueva investigación con una visión integral de los problemas y desafíos citados con objeto de proponer un desarrollo económicamente eficiente a escala tanto municipal y regional tanto en el corto como medio plazo (NWO, 2014). En ese sentido, ya se está trabajando en las estimaciones de las demandas residenciales y de oficinas para el periodo 2015-2020 (Programmabureau StedenbaanPlus 2014, 2013).

\section{EL CASO DE KARLSRUHE (ALEMANIA)}

El modelo tranviario Das Karlsruher Modell se encuentra en la ciudad de Karlsruhe, de unos 300.000 habitantes, situada en el suroeste de Alemania en el estado de Baden-Wutenberg.

Das Karlsruher Modell es un sistema de tranvitrén que circula sobre la infraestructura ferroviaria de trenes regionales existente, aunque con características duales en función de su trayectoria. Específicamente, se comporta como un tranvía convencional en el centro urbano de Karlsruhe, con velocidades mínimas $30 \mathrm{~km} / \mathrm{h}$, y puede alcanzar los $100 \mathrm{~km} / \mathrm{h}$ cuando circula fuera del centro urbano. Este sistema nace como respuesta a la solución del tráfico urbano de la ciudad y se trata del primer tranvitrén de Europa, conocido como Sistema Dual (Sweisystem) debido a su comportamiento como tranvía, o bien, como tren ligero (Bugarín y Rodríguez, 2008).

Antes de su implantación, la ciudad disponía de una red de metro ligero consolidada, así como de unos servicios ferroviarios regionales que comunicaban algunos de los núcleos del área metropolitana con la estación ferroviaria de Karlsruhe (situada a $2 \mathrm{~km}$ al sur del centro). Los usuarios de estos servicios regionales debían realizar un transbordo al metro ligero en la citada estación de ferrocarril para llegar al centro de la ciudad. Por ello, la demanda de estos servicios era reducida y se limitaba a los usuarios cautivos, es decir, aquellos que no tenían otra alternativa de transporte (Christoffel y Glaser, 2008).

El 25 de Septiembre de 1992 tuvo lugar la apertura de la primera línea piloto del sistema de tranvitrén, que unió el centro urbano de la ciudad de Karlsruhe con el cercano núcleo de Bretten, ubicado a $25 \mathrm{~km}$ y con una población del orden de diez veces menor. Antes de 1992, como se observa en la Fig. 9, las poblaciones, Karlsruhe y Bretten estaban conectadas únicamente por el ferrocarril convencional, mediante líneas de cercanías, con un trazado perimetral (KVV, 2012). 


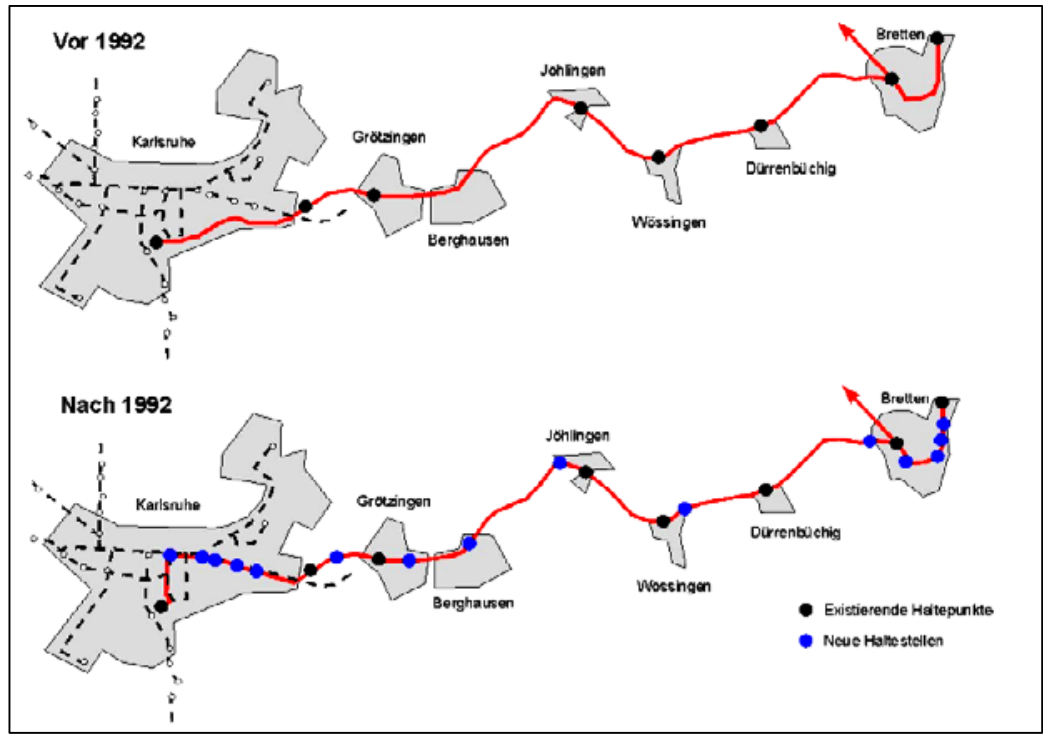

Fuente: KVV, 2012.

Esta línea piloto de tranvitrén experimentó durante su primer año un éxito masivo de pasajeros, con un incremento superior al 400\%: de 1.700 pasajeros diarios en 1991, pasó a transportar 7.000 en 1993 y actualmente cuenta con 17.500. Fundamentalmente, su éxito radica en que el origen-destino del $70 \%$ de los pasajeros se sitúa en este corredor, sin necesidad de efectuar transbordos intermodales (SISKA, 2011). Además, la versatilidad de este sistema de transporte, que permite vertebrar la ciudad transversalmente, hace que resulte muy competitivo en tiempo de desplazamiento puerta a puerta con el vehículo privado.

Consecuentemente, este pionero sistema de tranvitrén (Sweisystem) ha remodelado también la configuración de la ciudad. En el caso de la línea que inauguró este modelo tranviario en 1992, se ha ejecutado, desde su implantación, un plan de ordenación urbana en el que se conjugan movilidad urbana y ordenación del territorio. Un ejemplo de este desarrollo urbano es el distrito de Nordstadt-Neureut (Fig. 10), que es el más joven de los 27 distritos que forman parte de la ciudad de Karlsruhe (Engehausen y Bräunche, 2008).

El distrito de Nordstadt-Neureut tiene una extensión de 267,31 hectáreas una densidad de población de 35 habitantes por hectárea y 9.400 habitantes. Nordstadt-Neureut es un área residencial donde se ha desarrollado el modelo urbano en el que el tranvía es el eje vertebrador de la ciudad: alrededor del tranvía encuentran emplazamiento viviendas, equipamientos, comercio y espacios verdes. En cuanto a las viviendas, 1.039 son unifamiliares y 4.156 pertenecen a edificios residenciales, con una ocupación media de 2,37 personas por vivienda y un índice de motorización de 378,6 vehículos por cada 1000 habitantes (SISKA, 2011). 


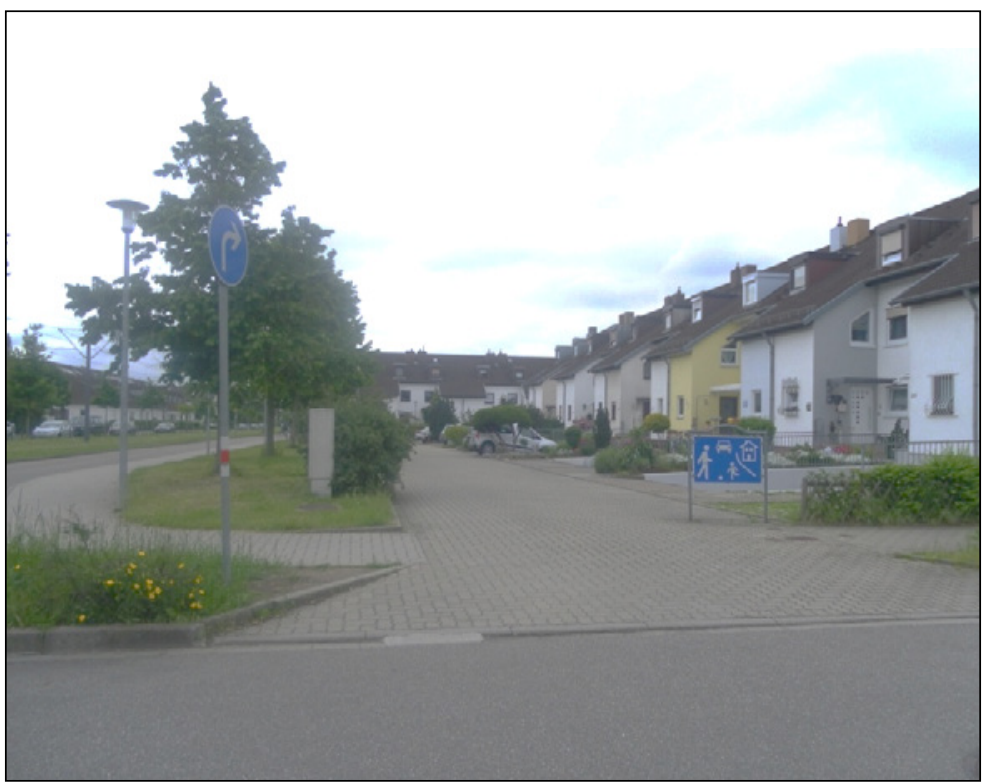

Foto de los autores.

Tras la implantación de la línea 3 de tranvitrén, se construyeron 5.000 nuevas viviendas a lo largo de los 3,1 km de longitud del trazado de la línea. Estas viviendas están orientadas a la línea ferroviaria, coexistiendo diversas tipologías: viviendas unifamiliares, edificios de tres plantas -como máximo- y viviendas de protección oficial, que ofrecen un carácter residencial al barrio (Christoffel y Glaser, 2008). También es posible encontrar escuelas, guarderías, oficinas, bibliotecas, centros de formación así como lugares de culto y comercios diversos, principalmente ubicados al inicio y al final de la línea.

\section{SÍNTESIS DE RESULTADOS Y CONCLUSIONES}

A lo largo de este artículo se han descrito diferentes intervenciones de TOD en distintos países, correspondiéndose con proyectos regionales en algunos casos mientras que en otros se han ceñido a los barrios de las estaciones.

Han sido varias las circunstancias comunes que han hecho posible el desarrollo de estas intervenciones en el ámbito internacional (Tabla 1): el compromiso del sector público (agencias de desarrollo regional y local), de las empresas públicas o privadas explotadoras del transporte público y la participación del sector inmobiliario, bien público o privado. Cuando alguno de estos elementos no ha estado presente desde el principio o bien su papel no ha sido relevante en la fase de planificación, la implantación del modelo ha sido mucho más complicada. 
Tabla 1

SÍNTESIS DE RESULTADOS

\begin{tabular}{|c|c|c|c|c|c|c|}
\hline TOD & $\begin{array}{l}\text { Othello } \\
\text { (Seattle) }\end{array}$ & $\begin{array}{l}\text { Ohlone- } \\
\text { Chynoweth } \\
\text { (San José) }\end{array}$ & $\begin{array}{c}\text { Centre } \\
\text { Commons } \\
\text { (Portland) }\end{array}$ & $\begin{array}{c}\text { Beaverton } \\
\text { Central } \\
\text { (Portland) }\end{array}$ & $\begin{array}{l}\text { Zuid- } \\
\text { Holland }\end{array}$ & Karlsruhe \\
\hline $\begin{array}{l}\text { Población ciudad/es } \\
\text { (habitantes) }\end{array}$ & 600.000 & 1.000 .000 & 600.000 & 600.000 & 500.000 & 300.000 \\
\hline $\begin{array}{l}\text { Población área } \\
\text { metropolitana/región } \\
\text { funcional urbana } \\
\text { (habitantes) }\end{array}$ & 3.000 .000 & 2.000 .000 & 2.000 .000 & 2.000 .000 & 4.000 .000 & 2.800 .000 \\
\hline $\begin{array}{l}\text { Distancia al centro } \\
\text { ciudad }(\mathrm{km})\end{array}$ & 10 & 10 & 8 & 8 & $\begin{array}{l}\text { Proyecto } \\
\text { regional }\end{array}$ & 7 \\
\hline $\begin{array}{l}\text { Compromiso del } \\
\text { sector público }\end{array}$ & Sí & Sí & Sí & Sí & Sí & Sí \\
\hline $\begin{array}{l}\text { Compromiso de la } \\
\text { entidad operadora de } \\
\text { transporte público }\end{array}$ & Sí & Sí & Sí & No & Sí & Sí \\
\hline $\begin{array}{l}\text { Consideración de } \\
\text { todos los niveles de } \\
\text { renta }\end{array}$ & Sí & Sí & Sí & No & Sí & Sí \\
\hline $\begin{array}{l}\text { Participación del } \\
\text { sector inmobiliario } \\
\text { (ej. ventajas fiscales) }\end{array}$ & Sí & Sí & Sí & Sí & No & No \\
\hline $\begin{array}{l}\text { Oferta de nuevas } \\
\text { viviendas de } \\
\text { protección oficial }\end{array}$ & Sí & Sí & Sí & No & Sí & Sí \\
\hline $\begin{array}{l}\text { Oferta de nuevas } \\
\text { viviendas en régimen } \\
\text { de alquiler }\end{array}$ & Sí & Sí & Sí & No & Sí & No \\
\hline $\begin{array}{l}\text { Integración de } \\
\text { calidad urbana en el } \\
\text { proyecto }\end{array}$ & Sí & Sí & Sí & Sí & Sí & Sí \\
\hline $\begin{array}{l}\text { Incremento de la } \\
\text { densidad urbana, } \\
\text { mayor mezcla } \\
\text { de usos y menor } \\
\text { dependencia de } \\
\text { vehículo privado. }\end{array}$ & Sí & Sí & Sí & Sí & Sí & Sí \\
\hline
\end{tabular}

Otro de los elementos importantes ha sido la ayuda pública para favorecer el desarrollo del proyecto, bien a través de incrementos de edificabilidad, subvenciones, fondos perdidos para la ejecución, créditos blandos o incluso exenciones de impuestos a la propiedad para los residentes durante un periodo de tiempo (Utter, 2009). Es decir, y como aspecto clave, desde 
el sector público se ha redireccionado el desarrollo urbanístico, se ha planteado cuándo, cómo y dónde debería tener lugar el crecimiento urbano y, a partir de ahí, se ha incentivado al sector privado para que efectivamente se desarrollase ese suelo frente a otros que no se consideraban apropiados de acuerdo con esa estrategia.

Por otro lado, los factores clave que determinan la posibilidad de implementación del modelo TOD, identificados así en la literatura existente y tomando como referencia primigenia el caso holandés (Zonneveld y Ortuño-Padilla, 2012), son los siguientes: forma de gobierno como estado unitario descentralizado, densidad de población media o elevada, sistema policéntrico de ciudades, transporte público gestionado por empresa privada concesionaria o por el propio sector público, autonomía en la planificación local y elevado número de estaciones de transporte público. Paralelamente y teniendo en cuenta los factores anteriores, se identifica la potencialidad de aplicación del modelo en determinados ámbitos españoles: la región funcional urbana Alicante-Murcia (Zonneveld y Ortuño-Padilla, 2012) o el área metropolitana de Alicante, con importantes relaciones tales como Alicante-San Vicente del Raspeig (Fernández-Morote et al., 2014) o Alicante-Benidorm (Ortuño, 2012).

Los resultados de los casos expuestos han sido, en términos generales, muy satisfactorios, tanto desde el punto de la movilidad como de la calidad de los espacios públicos. Cabe, sin embargo, apreciar que, según el trabajo de campo realizado, en Estados Unidos la aplicación del proyecto de TOD (Reconnecting America, 2011) llega tarde debido a la dimensión que alcanza la baja densidad y al diseño del espacio público, perfectamente orientado hacia el uso del vehículo privado. Estos factores provocan que los proyectos de TOD llevados a cabo sean casi anecdóticos en ese predominio de baja densidad. Sin embargo, en Europa, si bien es cierto que la baja densidad se ha desarrollado intensamente durante las últimas décadas (EEA, 2010), todavía no se ha llegado al extremo americano, por lo que se entiende que se está a tiempo de aplicar el modelo.

Más si cabe en el caso de España, donde el crecimiento de la baja densidad desde la década de los noventa ha sido muy preocupante, especialmente en el centro peninsular y en el litoral mediterráneo (EEA, 2006). En estas zonas, donde: se conjugan bajas densidades y una alta población residencial y turística, se han realizado grandes inversiones en transporte público (líneas de metro, tranvía, cercanías y regionales, además de los servicios de autobús) y el sector privado ha tenido una presencia muy notable en el diseño de las gran operaciones urbanísticas, el modelo TOD surge como gran oportunidad para reorientar las pautas de los desarrollos urbanos, de manera que, como se ha argumentado, debería ser el sector público el que tomara la riendas de las planificación, buscando el compromiso del sector privado bajo alguna de las fórmulas aplicadas en otros países donde ha sido exitoso.

\section{BIBLIOGRAFÍA}

ATELIER ZUIDVLEUGEL (2007): «Space and Line». Novaterra Connected Cities 11, 11-16. BAE, PITTMAN y HAMES (1999): Market analysis of the southeast corridor transit station areas. Seattle. The city of Seattle.

BREZNAU, S. (2004): «The San Jose Case Study: Ohlone-Chynoweth Station», en The new transit town: Best practices in Transit-Oriented development (Dittmar, H., Ohlan, G., coord.). Washington D.C. (EE.UU.), Island Press, 193-209. 
BUGARÍN, A. y RODRÍGUEZ, A. (2008): «Tranvitrén y tren-tranvía. Hacia una mejora del aprovechamiento de las infraestructuras ferroviarias», en Comisión de Transportes 6. Colegio de Ingenieros de Caminos, Canales y Puertos.

CALTHORPE, P. (1993): The Next American Metropolis. Ecology, Community and the American Dream. New York (EE.UU.). Princeton Architectural Press.

CASABELLA, N. y FRENAY, P. (2009): «Regional planning choices: comparing the RER in Brussels (BE) and the Stedenbaan in South-Holland (NL)». The 4th International Conference of the International Forum on Urbanism (IFoU). Amsterdam/Delft, 26-28 noviembre.

CERVERO, R. y KOCKELMAN, K. (1997): «Travel demand and the 3Ds: density, diversity and design». Transportation Research - D, Vol. 2, (3), 199-219.

CITY AND COUNTY OF DENVER (2006): Community planning and development, transit oriented development strategic plan.

CITY OF SEATTLE (2014): Envisioning Othello. Link Light Rail in Seattle neighborhoods. Disponible en http://www.seattle.gov/transportation/SAP/Othello.pdf

CONNECTED CITIES (2014): Disponible en http://connectedcities.eu/showcases/stedenbaan.html

COSTER, O. (2013): «Bicycle accessibility of train stations in the Randstad South Wing of the Netherlands: quantifying the use of the bicycle as access mode». University of Twente.

CHRISTOFFEL, M. y GLASER O. (2008): «Verkehrsbauten in satätenbaulich besonders sensible Stadträumen». Der Nahvekehr, vol. 26 (6), 25-37.

CURTIS, C. (2012): «Delivering the "D" in transit-oriented development. Examining the town planning challenge». The Journal of Transport and Land Use, Vol. 5 (3), 83-99.

DEPARTMENT OF TRANSPORTATION CALIFORNIA GOVERNMENT (2014). Disponible en http://transitorienteddevelopment.dot.ca.gov/station/stateViewStationServices. jsp?stationId=17

DEPARTMENT OF TRANSPORTATION SEATTLE GOVERNMENT (2014). Disponible en http://www.seattle.gov/transportation/ppmp_sap_neigh.htm

DILL, J. (2006): Final Technical Report. Travel and Transit Use at Portland Area TransitOriented Developments (TODs). Seattle. University of Washington.

EEA, European Environment Agency (2006): Urban Sprawl in Europe. The Ignored Challenge. Copenhagen.

EEA, European Environment Agency (2010): The European Environment. State and Outlook 2010. Land Use. Copenhagen.

ENGEHAUSEN, V.F. y BRÄUNCHE, E.O. (2008): 1933 - Karlsruhe und der Beginn des Dritten Reiches. Karlsruhe. G. Braun Verlag.

FERNÁNDEZ-MOROTE, G., ORTUÑO-PADILLA, A., FERNÁNDEZ-ARACIL, P. y MELGAREJO-LÓPEZ, A. (2014): «Implantación del Modelo Transit Oriented Development en San Vicente del Raspeig-Universidad de Alicante». XI Congreso de Ingeniería del Transporte. Santander, 9-11 junio.

GEURS, K., MAAT, K., RIETVELD, P. y VISSER, G. (2012): «Transit-Oriented Development in the Randstad South Wing: goals, issues and research». Conference Building the Urban Future and Transit-Oriented Development. París, 16-17 abril. 
GIBSON, K. y ABBOTT, C. (2002): «City profile: Portland, Oregon». Cities, vol. 19 (6), 425-436.

GRADY, S. y LEROY, G. (2006): Making the connection: transit-oriented development and jobs. Good Jobs First. Disponible en http://www.hud.gov/offices/cpd/about/conplan/pdf/ todjobs.pdf

HEINS, S., VAN DAM, F. y GOETGELUK, R. (2002): «The pseudo-countryside as a compromise between spatial planning goals and consumers' preferences». Built Environment, $\mathrm{n}^{\mathrm{o}} 28,311-318$.

HENRY, G. (2007): «Los costes económicos y sociales de la ciudad de baja densidad», en Indovina, F. (Ed.), La ciudad de baja densidad. Lógicas, gestión y contención, Barcelona, Diputació de Barcelona, 203-228.

HOWLEY, P. (2009): «Attitudes towards compact city living: Towards a greater understanding of residential behaviour». Land Use Policy, vol. 26 (3), 792-798.

KVV, Karlsruhe Verkehrs Verbund (2012): Präsentation Vortragzur Stadtbahn Karlsruhe, 22 May.

METRO (2014): Disponible en http://www.oregonmetro.gov/tools-partners/grants-andresources/transit-oriented-development-program

MOLINÍ, F. y SALGADO, M. (2010): «Superficie artificial y viviendas unifamiliares en España, dentro del debate entre ciudad compacta y dispersa». Boletín de la Asociación de Geógrafos Españoles, no $54,125-147$.

NATIONAL RESEARCH COUNCIL (2002): «Transit-Oriented Development and Joint Development in the United States: A Literature Review». Transit Cooperative Research Program. Research Results Digest, 52.

NATIONAL RESEARCH COUNCIL (2004): «Transit-Oriented Development in the United States: Experiences, Challenges, and Prospects». Transit Cooperative Research Program. Transport Research Board, 102.

NWO, The Netherlands Organisation for Scientific Research (2014): Disponible en http:// www.nwo.nl/en/research-and-results/research-projects/47/2300171647.html

OREGON METRO (2011): Transit-Oriented Development Program. Strategic Plan. Disponible en http://www.oregonmetro.gov/sites/default/files/tod_strat_plan_execsum.pdf

OREGON METRO (2012a): Transit-Oriented Development. Project investment criteria. Disponible en http://www.oregonmetro.gov/sites/default/files/14071_tod_investment_ criteria_aug2012.pdf

OREGON METRO (2012b): Transit-Oriented Development. Project profile. Center Commons. Disponible en http://www.oregonmetro.gov/sites/default/files/centercommons_ final.pdf

OREGON METRO (2014): Transit-Oriented Development Program. Annual Report. Disponible en http://www.oregonmetro.gov/sites/default/files/TOD-program-AnnualReport-2014.pdf

ORTUÑO, A. (2012): «Propuesta de remodelación ferroviaria AVE Aeropuerto-Alicante Benidorm». X Congreso de Ingeniería del Transporte. Granada, 20-22 junio.

PROGAMMABUREAU STEDENBAAN (2011): Stedenbaan monitor 2011. Platform Zuidvleugel. La Haya. 
PROGRAMMABUREAU STEDENBAANPLUS 2014 (2013): Stedenbaan monitor 2013. Platform Zuidvleugel. La Haya.

PUTTERS, B. (2008): «U.S.: some best practices of Transferable Development Rights», en New instruments in spatial planning. An international perspective on non-financial compensation (Janssen, L., Spaans, M., Van der Veen, M., coord. Amsterdam, IOS Press, 229-254.

RECONNECTING AMERICA (2011): Jumpstarting the Transit Space Race: 2011, A Catalog and Analysis of Planned and Proposed Transit Projects in the US. Washington, DC: Reconnecting America. Disponible en http://reconnectingamerica.org/assets/ 2011TransitSpaceRaceIIFinal.pdf

RENNE, J.L. (2009): «Introduction», en Transit-Oriented Development. Making it Happen (Curtis, C., Renne, J.L., Bertolini, L., Coord.). Farnham (Inglaterra) y Burlington (EE. UU.), Ashgate, 3-12.

RUEDA, S. (2007): «Plan especial de indicadores de sostenibilidad ambiental de la actividad urbanística de Sevilla», Agencia de Ecología Urbana de Barcelona. Sevilla: Ayuntamiento de Sevilla.

SORIA, A. (1882): «Causas de la carestía de la vida madrileña. Madrid remendado, Madrid nuevo». El Progreso (6 de marzo).

SORIA, A. (2004): Tratados de Urbanismo y Sociedad. Clan. Madrid.

SOUND TRANSIT (2014): Transit-Oriented Development (TOD) Program, Strategic Plan Update. Disponible en http://www.soundtransit.org/Documents/pdf/projects/tod/ 20140423_RPT_TOD.pdf

SISKA, Statistisches Informationssystem Karlsruhe (2011): Geschäftsbericht der Verkehrsbetriebe Karlsruhe. Disponible en http://web1.karlsruhe.de/Stadtentwicklung/siska/

URBAN UNLIMITED (2005): Environmental differentiation along the Stedenbaan. Mobility styles and chainprogrammes on the right track. Utrecht University.

UTTER, M. (2009): «Developing TOD in America: The Private Sector View», en TransitOriented Development. Making it Happen (Curtis, C., Renne, J.L., Bertolini, L., Coord.). Farnham (Inglaterra) y Burlington (EE.UU.), Ashgate, 209-223.

ZONNEVELD, W. (2010): «The Randstad and the South Wing: A soft space for planning?». 24th AESOP Annual Conference, Helsinki, 7-10 julio.

ZONNEVELD, W. y ORTUÑO-PADILLA, A. (2012): «TOD implementation possibilities in Alicante province and Murcia region (Spain) according to Stedenbaan experience (The Netherlands)». Conference Building the Urban Future and Transit-Oriented Development. París, 16-17 abril. 
